\title{
In vitro activity of xanthorrhizol isolated from the rhizome of javanese turmeric (Curcuma xanthorrhiza Roxb.) against Candida albicans biofilms.
}

\begin{abstract}
The purpose of this study was to investigate the activity of xanthorrhizol isolated from Curcuma xanthorrhiza Roxb. on Candida albicans biofilms at adherent, intermediate, and mature phase of growth. C. albicans biofilms were formed in flat-bottom 96-well microtiter plates. The biofilms of $\mathrm{C}$. albicans at different phases of development were exposed to xanthorrhizol at different concentrations $(0.5 \mu \mathrm{g} / \mathrm{mL}-256 \mu \mathrm{g} / \mathrm{mL})$ for $24 \mathrm{~h}$. The metabolic activity of cells within the biofilms was quantified using the XTT reduction assay. Sessile minimum inhibitory concentrations (SMICs) were determined at 50\% and $80 \%$ reduction in the biofilm OD490 compared to the control wells. The SMIC50 and SMIC80 of xanthorrhizol against $18 \mathrm{C}$. albicans biofilms were $4-16 \mu \mathrm{g} / \mathrm{mL}$ and $8-32 \mu \mathrm{g} / \mathrm{mL}$, respectively. The results demonstrated that the activity of xanthorrhizol in reducing $\mathrm{C}$. albicans biofilms OD490 was dependent on the concentration and the phase of growth of biofilm. Xanthorrhizol at concentration of $8 \mu \mathrm{g} / \mathrm{mL}$ completely reduced in biofilm referring to XTTcolorimetric readings at adherent phase, whereas $32 \mu \mathrm{g} / \mathrm{mL}$ of xanthorrhizol reduced $87.95 \%$ and $67.48 \%$ of biofilm referring to XTT-colorimetric readings at intermediate and mature phases, respectively. Xanthorrhizol displayed potent activity against C. albicans biofilms in vitro and therefore might have potential therapeutic implication for biofilm-associated candidal infections.
\end{abstract}

Keyword: Amphotericin B; Biofilm; Candida albicans; In vitro; Xanthorrhizol. 